\title{
Surrendering with Statistics! Are University Students Stooping in with a Deficit? A Preliminary Analysis of the Constraints at a University in a Developing Country
}

\author{
Mr R. Chifurira \\ School of Mathematics, Statistics and Computer Sciences, University of KwaZulu - Natal, \\ Private Bag X54001 Durban 4000, South Africa \\ Email: chifurira@gmail.com \\ Mr I. Mudhombo \\ Faculty of Management Sciences: Vaal University of Technology \\ Private Bag X021, Vanderbijlpark, 1900, South Africa \\ Email: imudhombo@yahoo.com \\ Ms M. Chikobvu \\ Faculty of Management Sciences: Vaal University of Technology \\ Private Bag X021, Vanderbijpark, 1900, South Africa \\ Email:marianc@vut.ac.za
}

Doi:10.5901/mjss.2014.v5n3p234

\begin{abstract}
This study aims to identify the barriers to success in statistics using exploratory factor analysis and regression modelling techniques. Students from a broad spectrum of specialities in universities take statistics as a course, the majority of them with poor mathematical background. A questionnaire was administered to 394 respondents in the faculty of management sciences at a university in South Africa. The study identified 6 factors namely disadvantaged background, cognitive capacity, access to resources, support structures, content difficulty and value of statistics as barriers to success in statistics. The factors disadvantaged background and cognitive capacity are classified as situational barriers. The factors access to resources and support structures are classified as organisational barriers. The factors access to resources and support structures are classified as organisational barriers. Regression modelling techniques reveals that factor cognitive capacity is influenced by the number of times a student has repeated statistics and the levels obtained in the mathematics in Grade 12 (Matriculation).
\end{abstract}

Keywords: Learning statistics; barriers; factor analysis; regression analysis.

\section{Introduction}

South Africa has 23 public universities spread throughout the country. In spite of substantial government economic support for education reform, glaring gaps left by 40 years of apartheid education still riddle South Africa's education system at every level. Primary and secondary schools that historically served black students typically perform poorly: Grade 12 pass rates for black students are often half of that of white students (National Diagnostic Report on Learner Performance, 2012). Analysis of throughput data indicates that fewer than 5 South Africans in 100 who enrol in Grade one of schooling graduate from university. This problem is particularly acute for disadvantaged students: only $28 \%$ of students in the National Student Financial Aid Scheme of South Africa (NSFAS) make it to graduation. A recent report of the Department of Higher Education and Training (DoHET) reflect that the average undergraduate graduation rate is around 15\% (DoHET annual Report, 2012/13). Among the various reasons for the low graduation rates include financial constraints, where students enrol for courses but do not have the funding to see them through, the lack of academic preparedness and inadequate support received by students from universities (Murdock, 2013). Of main concern is that numerous students perform poorly in mathematics and mathematics related subjects such as statistics.

Statistics has impacted the curriculum in all level education fields (Tsao, 2006). The ability to collect, organise, analyse, interpret and present data has become an important component of many studies and careers (Giesbrecht, 1996). Many students face difficulties with basic mathematics computations, mathematical language and use of 
calculators, hence, cannot analyse and interpret data correctly. The general pass rate in most universities is below $50 \%$. The subject is regarded as at risk subject at many universities. Some universities have tried to add extra lecturing periods and tutorial sessions but to no avail. The question is: what are the underlying barriers to success in statistics? Universities expect pass rates to be above $80 \%$. The low pass rate in statistics maybe partly due to student's prior mathematical skills which are below standard, lack of interest among the students, the quality of the lecturers, lack of understanding the importance of statistics to their studies and careers (Baker et al 2010). Statistics induces fear to many people (Schutz and Koshino, 1998). Stootmaekers (2012) urges that there is evident fear of statistics among university students. At universities of technology, the fear is even huge amongst students taking commercial and social subjects considering that they lack a sound mathematical foundation. Universities are faced with high number of students repeating statistics modules, thus inflating their enrolments with large class sizes. Statistics is a key subject which unlocks many other subjects. Just a mere analysis on the pass rates, one can conclude that a high number of students fail to graduate in universities of technology because of failing statistics. Not only is statistics important for students to pass their programmes, numeric skills are important to avoid deception and to function in society (Stootmaekers, 2012). To promote a lifelong learner, students need to sharpen their statistical skills and overcome barriers to success in statistics. Statistics and quantitative techniques is the cornerstone for research.

Research has previously been undertaken on the attitude of students in universities towards statistics, mostly using Survey of Attitude Towards Statistics (SATS-36) questionnaire (Vanhoof, et al., 2011). Slootmaeckers (2012) investigated student's attitude towards statistics as a barrier to acquiring quantitative skills for social science students and found that the attitudes towards statistics have an effect on the learning of statistics and on the long term retention of quantitative methods.

Estrada and Batanero (2008) investigated attitudes towards statistics among Spanish teachers. The study revealed that there might be problems in Spain as regards to teachers' statistical knowledge and attitudes. If teachers have challenges in statistical knowledge and negative attitude there is a high likelihood that they might transmit the same attitudes to their students. Gracia-Santillan et al. (2013) identified variables using exploratory factor analysis to explain the attitude towards statistics in undergraduate students in Mexico. The study revealed two factors namely, favourable attitude towards statistics comprised three factors (usefulness, anxiety and confidence) and unfavourable attitude towards statistics comprised two factors (anxiety and motivation). Emmioglu (2011) investigated the structural relationships among mathematics achievement, attitudes towards statistics and statistics outcomes. The study showed significant correlation among mathematics achievement, affect, value and interest and the effort variables.

The central argument of this study is that the learning environment is different and mathematical background is poor in developing countries, hence the justification of this study. No literature was found on determining barriers to the learning of statistics focusing on students in Southern Africa, especially amongst the previously disadvantaged racial groups. Therefore, the importance of this study is to identify the barriers to success in statistics at universities of Technology among the commerce students in a developing country. This study also seeks to develop regression models that explain the barriers to success in statistics.

This study is not only enrichment to knowledge but will assist statistics teachers at universities to be aware of the obstacles these students are facing so as to design effective activities that will spark students interest in statistics and improve the results.

The rest of the paper is organised as follows: In the next section a brief overview of the literature on barriers to success is presented followed by a section that explains the research design and methodology. This is followed by a section that reveals the results of the barriers to success in statistics. In the last section conclusions and recommendations are made.

\section{Barriers to learning}

A barrier to learning is anything that obstructs or impedes access or progress in acquiring knowledge or skills (Burton et al., 2010). These can be summarised as relating to personal and family circumstances, geographical, study experiences both past and present. McGiveney (1990), Cross (1981) and Maxted (1999) described key barriers to learning and categorised them as situational, institutional, dispositional and organisational barriers.

\subsection{Situational barriers}

Cross (1981) defined situational barriers as those barriers, which relate to a person's life context at a particular time, 
including both the social and physical environment surrounding one's life. Examples of situational barriers include lack of transportation for attending lectures on campus, cost of education, and lack of time management.

\subsection{Institutional barriers}

Institutional barriers are those set up by learning institutions that exclude or discourage certain groups of learners because of schedules, being a full-time student, fees and confusing financial aid processes (Cross, 1981). Lack of attractive or practical courses, inaccessible locations, unclear registration processes and procedures and inadequate student support services are some of the institutional barriers encountered by learners at tertiary level.

Another institutional barrier is related to the entry-level criteria or approval requirements to enrol in university programs. Programs that have statistics as a course require a minimum of a grade 12 Mathematics or Mathematics Literacy with a certain or specific grade, although some Universities grant credit for prior learning for some or mature learners.

\subsection{Dispositional barriers}

The dispositional barrier as described by Cross (1981) relates to the learners' beliefs, values, attitudes and perception of self. Dispositional barriers can also refer to the attitudes and values of not only of the learner but also their important others, the community and educational providers (Estrada and Batanero, 2008). Attitudinal barriers are viewed as the result of some insufficiency on the part of the learner. Mcleod (1992) cited in Estrada and Batanero (2008) distinguished attitudes as learned predispositions to respond positively or negatively to given objects, situations, concepts, or persons. Attitudes, thus is multi-dimensional that comprise the cognitive (beliefs or knowledge), affective (emotional or motivational), and performance (behaviour or action) dimensions (Aiken, 1980). The student's experiences (in statistics) both in the classroom and outside classroom determine their attitude towards the subject. This has a huge impact on retention of statistical concepts in future and pursuing statistically related further studies.

Dispositional barriers, which are also referred to as psychosocial barriers (Darkenwald and Merriam, 1988), are described as low self-esteem and self-confidence; negative attitudes towards their situation as a learner, such as being too sick, too busy, or not smart enough. Dispositional barriers may also refer to previous negative school experience, low motivation, embarrassment and a fear of failure or a lack of support from family and friends. Cross (1981) suggests that this category is far more influential in student participation and success.

\subsection{Organisational barriers}

Student and teacher concerns represent the human aspects of learning. Organizational problems such as infrastructure and technology complications, also present challenges to the learning process. Technology problems include; financing new technology, telecommunications, hardware issues, course construction and technology and Internet problems (Galusha, 1998).

A major concern for both learning institutions and students is availability of funds. When technology is used, the costs increase substantially for both the student and the institution. Therefore, universities must consider the initial costs as well as the continuing costs of installing, maintain, using and upgrading technology to support effective learning (Galusha, 1998).

\section{Method}

\subsection{Setting}

A study has been carried out amongst students taking statistics and quantitative techniques in the Faculty of Management Sciences at a University in South Africa. It is one of the larger universities of technology in South Africa with an annual enrolment of about 21000 students.

\subsection{Procedure}

A questionnaire on students' perception and experience with statistics and socio-demographic questions was 
administered. The questionnaire constructed had only closed questions to which participants responded on a Likert-type scale from strongly disagree (1) to strongly agree (5). A reverse scoring procedure was used in some questions because of negatively worded questions. This type of questionnaire was chosen because it is quick to complete and administer (Wilson and Mclean, 1994).

To improve internal validity of the questionnaire, pilot survey was done. Clarity and ambiguities in the questions were addressed. The questionnaire was corrected using recommendations from the pilot survey.

Students were informed of the rationale of the questionnaire. Confidentiality of the responses was guaranteed and their consent sort before administering the questionnaire. Respondents were stratified according to enrolled programmes (Accounting, Marketing and Safety management). Within each stratum (programme) a random sample of 150 respondents were selected using systematic sampling techniques. Class registers were used as the sampling frame. A total of 450 students were selected and questionnaires administered. Ethical considerations regarding confidentiality and the right to withdraw from the survey were adhered to. Permission to undertake the survey was sought and granted from the Dean's office and Ethics committee of the university.

\subsubsection{Factor Analysis}

This paper employs factor analysis to identify the barriers to success in statistics. Factor analysis is a statistical tool used to study the dimensionality of a set of variables (Browne, 2001). In factor analysis, latent variables represent unobserved constructs and are referred to as factors or dimensions. In this study, Principal Component Analysis is used to explore the dimensionality of the questionnaire by finding the smallest number of interpretable factors needed to explain the correlations among a set of variables. The interpretability of the factors is improved by rotation. Varimax rotation was used as it maximises the loadings of each variable on one of the extracted factors whilst minimising the loadings on other factors.

\subsection{Data Analysis}

The data were analysed in the following ways: a descriptive analysis of the sample was undertaken. Factor analysis was undertaken to establish the factors that contributed to barriers to success in statistics. Regression analysis was carried out to model the barriers to success in statistics as dependent variables using course related items.

\section{Results}

In this section the findings of the study are presented.

\subsection{Descriptive statistics}

A summary of demographic characteristics of the respondents (Table 1 ) indicated that $44.2 \%$ of the respondents were males and $55.8 \%$ were females. After summarising the age categories of the respondents, the largest percentage (87.1\%) identified themselves in the 21-30 years age group. Of the 394 respondents, $27.2 \%$ are enrolled for a marketing qualification $23.9 \%$ for safety management qualification and $49.0 \%$ for accounting qualification. The majority of the respondents (83.0\%) preferred English as their language of instruction and communication. Only $16 \%$ of the respondents preferred their mother-tongue language for instruction and communication.

Table 1. Demographic information of the respondents

\begin{tabular}{|c|c|c|c|c|}
\hline Variable & Category & $N$ & $n$ & $\%$ \\
\hline \multirow[t]{2}{*}{ Gender } & Male & 394 & 174 & 44.2 \\
\hline & Female & 394 & 220 & 55.8 \\
\hline \multirow[t]{4}{*}{ Age Group } & Less than 20 years & 394 & 46 & 11.7 \\
\hline & $21-30$ years & 394 & 343 & 87.1 \\
\hline & $31-40$ years & 394 & 3 & 0.8 \\
\hline & Over 40 years & 394 & 2 & 0.5 \\
\hline
\end{tabular}




\begin{tabular}{|c|c|c|c|c|}
\hline Qualification Enrolled & $\begin{array}{l}\text { Marketing } \\
\text { Safety Management } \\
\text { Accounting (Internal Auditing, Financial Information Systems, Cost } \\
\text { Management and Accounting ) }\end{array}$ & $\begin{array}{l}394 \\
394 \\
394\end{array}$ & $\begin{array}{c}107 \\
94 \\
193\end{array}$ & $\begin{array}{l}27.2 \\
23.9 \\
49.0\end{array}$ \\
\hline $\begin{array}{l}\text { Preferred Language of } \\
\text { Communication }\end{array}$ & $\begin{array}{l}\text { English } \\
\text { Mother tongue } \\
\text { Other Language }\end{array}$ & $\begin{array}{l}394 \\
394 \\
394\end{array}$ & $\begin{array}{c}327 \\
63 \\
4\end{array}$ & $\begin{array}{c}83.0 \\
16.0 \\
1.0\end{array}$ \\
\hline
\end{tabular}

\subsection{Factor Analysis}

The Kaiser-Meyer-Olkin (KMO) statistic of sampling adequacy was undertaken to establish whether the data were suitable for a multivariate procedure. KMO measure of sampling was calculated at $(0.73)$ which is regarded as satisfactory by Kaiser (1974). The Bartlett's test of sphericity $(p=0.000)$ was significant and therefore the data set was appropriate for factor analysis. A low loading variable reduction process was used to reduce the number of variables in order to produce a more stable factor structure. Items that did not load on any factor with at least a loading of 0.50 were deleted from the item set. This procedure resulted in six distinguishable factors with eigenvalue greater than 1 . These factors were labelled as disadvantaged background (F1), cognitive capacity (F2), access to resources (F3), content difficulty (F4), value of statistics (F5) and support structures (F6). The rotated factor loading matrix illustrating the resultant factors, eigenvalues, reliabilities and means are provided in Table 2.

Table 2. Rotated Factor loading Matrix

\begin{tabular}{|c|c|c|c|c|c|c|c|c|c|}
\hline Variable description & F1 & F2 & F3 & F4 & F5 & F6 & $\begin{array}{l}\text { Item-total } \\
\text { correlation }\end{array}$ & $\begin{array}{l}\text { Cronbach Alpha if } \\
\text { item deleted }\end{array}$ & $\begin{array}{l}\text { Mean } \\
\text { Rank }\end{array}$ \\
\hline I suffer from physical abuse & .880 & .038 & -.031 & .160 & .034 & -.036 & .328 & .725 & 20 \\
\hline \begin{tabular}{|l} 
suffer from sexual abuse \\
\end{tabular} & .851 & .022 & -.072 & .113 & -.076 & -.082 & .247 & .727 & 19 \\
\hline I suffer from verbal abuse & .822 & .038 & -.044 & .122 & -.011 & -.067 & .287 & .726 & 18 \\
\hline I suffer from emotional abuse & .643 & .237 & -.050 & .044 & -.075 & -.129 & .214 & .728 & 16 \\
\hline $\begin{array}{l}\text { I easily get mental block in identifying ways of solving } \\
\text { statistical problems }\end{array}$ & .096 & .837 & -.024 & .107 & -.058 & -.083 & .243 & .726 & 13 \\
\hline $\begin{array}{l}\text { I often get a mental block in identifying the type of } \\
\text { statistical problem }\end{array}$ & .083 & .824 & -.087 & -.002 & .058 & -.016 & .244 & .726 & 12 \\
\hline $\begin{array}{l}\text { I easily give up if I find it difficult to solve a statistics } \\
\text { problem }\end{array}$ & .017 & .610 & .029 & .142 & -.148 & -.010 & .150 & .730 & 13 \\
\hline $\begin{array}{l}\text { I easily forget important statistical procedures when I am } \\
\text { writing a statistical assessment task }\end{array}$ & .087 & .586 & -.063 & .243 & -.076 & -.061 & .220 & .727 & 11 \\
\hline I have access to the internet & -.096 & -.065 & .788 & -.078 & .032 & .085 & .105 & .732 & 4 \\
\hline I have access to the library & -.124 & -.015 & .781 & -.031 & 028 & .035 & 114 & 731 & 2 \\
\hline I have access to statistical books & -.026 & .001 & .712 & -.010 & .112 & -.021 & .207 & .728 & 8 \\
\hline I have adequate time to study at my place of residence & .057 & -.059 & .602 & -.188 & .109 & .076 & .133 & .731 & 9 \\
\hline I have difficulty in remembering concepts & .063 & .130 & -.102 & .785 & .008 & -.128 & .176 & .729 & 15 \\
\hline I have difficulty in communicating in English language & .354 & -.057 & -.129 & .658 & .057 & -.014 & .255 & .727 & 17 \\
\hline I have difficulty in concentrating in class & .133 & .177 & -.074 & .642 & -.166 & .046 & .123 & .731 & 14 \\
\hline $\begin{array}{l}\text { I have difficulty in performing basic mathematical } \\
\text { calculations }\end{array}$ & .022 & .321 & -.044 & .594 & -.049 & -.029 & .152 & .730 & 14 \\
\hline Statistics adds value to my future & .063 & -.089 & .029 & -.148 & .789 & .121 & .191 & .729 & 6 \\
\hline Statistics adds value to my diploma & -.067 & -.033 & .094 & .048 & .785 & -.016 & .146 & .730 & 1 \\
\hline I always do my statistics assignment & -.084 & -.084 & .148 & -.043 & .674 & .101 & .169 & .729 & 3 \\
\hline I receive social support from my family & -.176 & -.090 & -.017 & .039 & .126 & .769 & .070 & .733 & 7 \\
\hline I receive financial support from my family & -.145 & -.113 & .114 & .049 & .071 & .766 & .110 & .732 & 5 \\
\hline I receive social support from my friends & .035 & .043 & .065 & -.195 & .014 & .711 & .191 & .728 & 10 \\
\hline Eigen values & 4.417 & 2.211 & 2.021 & 1.715 & 1.399 & 1.331 & \multirow{5}{*}{\multicolumn{3}{|c|}{ Overall Cronbach Alpha $=0.732$}} \\
\hline$\%$ of variance explained & 20.078 & 10.048 & 9.188 & 7.795 & 6.359 & 6.051 & & & \\
\hline Cumulative $\%$ of variance & 20.078 & 30.127 & 39.314 & 47.109 & 53.468 & 59.519 & & & \\
\hline Reliability (Cronbach $\alpha$ ) & .810 & .726 & .712 & .643 & .680 & .655 & & & \\
\hline $\begin{array}{l}\text { Loadings above } 0.50 \text { were considered significant load } \\
\text { varimax. Rotation -Principal factor analysis }\end{array}$ & & & & & & & & & \\
\hline
\end{tabular}

$$
\mathrm{F}=\text { Factor }
$$


Table 3 shows the extracted factors and their operational definitions.

Table 3. Extracted factors and their definitions

\begin{tabular}{|c|l|}
\hline Factor & \multicolumn{1}{c|}{ Description } \\
\hline $\begin{array}{c}\text { Disadvantaged } \\
\text { background }\end{array}$ & $\begin{array}{l}\text { This factor refers to the experiences of the students that might disadvantage them in their studies. The } \\
\text { factor is combination of the student having a background of physical abuse, sexual abuse, verbal abuse } \\
\text { and emotional abuse. }\end{array}$ \\
\hline Cognitive capacity & $\begin{array}{l}\text { This factor refers to the individual student's intellectual capacity to cope with statistics. The factor is } \\
\text { composed of the aspects of students having mental block when identifying ways to solve statistics, } \\
\text { easily forget important statistics procedures and also easily giving up when they find it difficult. }\end{array}$ \\
\hline $\begin{array}{c}\text { Access to } \\
\text { resources }\end{array}$ & $\begin{array}{l}\text { This factor relates to the accessibility to the Internet, library, statistics books and having adequate time } \\
\text { to study by the students }\end{array}$ \\
\hline Support structures & $\begin{array}{l}\text { The factor refers to the support students get from stakeholders such as social support and financial } \\
\text { support from family and/or friends. }\end{array}$ \\
\hline Content difficulty & $\begin{array}{l}\text { The factor 'content difficulty' relates to issues relating to the difficulty in remembering concepts, difficulty } \\
\text { in concentrating in class and difficulty in performing basic mathematics calculations. }\end{array}$ \\
\hline Value of statistics & The factor refers to how important statistics is to the student's future and their qualifications. \\
\hline
\end{tabular}

\section{Discussion}

In analysing the respondents' views on barriers to success in statistics, six factors were identified namely disadvantaged background, cognitive capacity, access to resources, support structures, content difficulty and value of statistics. The description of the factors is outlined in Table 3 . The factors are broadly classified into situational, organisational and dispositional barriers. These factors accounted for approximately $60 \%$ of variance. This is in line with the recommendations of Maholtra and Birks (2007) that the cumulative percentage of variance extracted by the factors be at least $60 \%$. The means for each item are ranked and reported in Table 2. The means reflect the location on a 5- point Likert scale.

\subsection{Situational barriers}

The factors disadvantaged background and cognitive capacity was classified as situational barriers as suggested by Cross (1981).

\subsubsection{Students disadvantaged background}

The factor 1, labelled disadvantaged background consists of four items that accounted for $20.078 \%$ of the variance. This is indicative of the important contribution that students with disadvantaged backgrounds play a role in impacting the success in statistic. The means of the factor disadvantaged background is an average of 1.4 which translates to a below moderate propensity for barrier to success in statistics. This finding is consistent with barriers identified in the National Committee on Education Support Services (NCESS) report of 1997. NCESS (1977) report identified factors which place learners at risk as a barrier to learning. Schaeffer (2011) using forensic interviews observed that abused children tend to withdraw themselves from others and participate less in groups. This has a direct impact on the performance of the student especially in statistics, a subject that requires high degree of interaction with others. Brown and Turk (2009) also supports the notion that even sexual activity involving people with learning disabilities is deemed abusive and acts as a barrier to learning.

\subsubsection{Cognitive capacity}

The factor 2 labelled cognitive capacity consist of 3 items and accounted for $10.048 \%$ of the variance. The means of the factor cognitive capacity is an average of 2.8 which translates to a moderate propensity suggesting that students believe that they easily give up or get a mental block in solving statistical problems. This finding is consistent with the findings of Vanhoof et al. (2011), and Estrada and Banatero (2008) which revealed that cognitive competence plays a crucial role in explaining attitudes towards statistics by teachers and students alike. 


\subsection{Organisational barriers}

The factors access to resources and support structures are classified as organisational barrier to success in statistics.

\subsubsection{Access to resources}

The Factor 3 labelled access to resources consists of 4 items and accounted for $9.188 \%$ of the variance. The means of the factor access to resources is an average of 4.0 which translates to a high propensity suggesting that students believe that access to resource is a key to success in statistics. This is consistent with Galusha (1998) who identified programme costs, resource availability and lack of equipment as barriers to learning. Stammen (1995) categorised barriers to learning as technical, relating to access to technology such as internet, structural. Horton (2001) argues that online learning such as via Internet and other information technologies create educational experiences for students. The reason is it makes learning affordable anywhere, at any place and at any time students may desire.

\subsubsection{Support Structures}

The factor 6 labelled support structures consists of 3 items and accounted for $6.051 \%$ of the variance. The means for the factor support structures is an average of 3.8 which above moderate propensity suggesting that students believe that family and friends support is essential in their studies. This is consistent with Hodkinson et al. (2006) who identified that support and guidance is essential especially for students who often have low self-esteem and confidence. Social and financial support need to be geared to individual students (Castles, 2004; Doyle and Taylor (2003). Davies et al. (2002) agrees that financial factors could impede on the students' learning progress.

\subsection{Dispositional barriers}

The factors content difficulty and value of statistics were classified as dispositional barriers to success in statistics.

\subsubsection{Content difficulty}

The factor 4 labelled content difficulty consists of 4 items and accounted for $7.795 \%$ of the variance. The means of the factor content difficulty is an average of 2.1 which translates to a moderate propensity suggesting that students believe that statistics content and lesson delivery is a barrier to their success in statistics. This is line with the studies by Khavenson (2012), Bell (2003) and Onwuegbuzie and Wilson (2003) that identified statistics prior knowledge, statistics course grades and content as a dispositional barrier to learning statistics.

\subsubsection{Value of statistics}

The factor 5 labelled value of statistics consists of 3 items and account for $6.359 \%$ of the variance. The means of the factor value of statistics an average of 4.2 which translates to a high propensity suggesting that students believe that statistics adds value to their qualifications and future careers. The findings of this study are consistent with the findings of Suanpang et al. (2004) which revealed that the value of statistics is moderately related to students' attitudes to learning business statistics.

\subsubsection{Regression analysis}

After factor analysis, regression analysis was undertaken to model the barriers to success (cognitive capacity) in statistics as dependent variables using course related factors as independent factors.

\subsubsection{Course related items}

Course related items such as how many times the student has been repeating Statistics, the subject done and grades obtained at grade 12 level are regressed against the factors. Table 4 shows the results of regressing course related items and factors. 
Table 4. Regression analysis of factor cognitive analysis as a dependent variable

\begin{tabular}{|l|c|}
\hline \multicolumn{1}{|c|}{ Course related variables } & Cognitive capacity \\
\hline I am doing statistics for the & $0.138^{* *}$ \\
Mathematical subject at Grade 12 & 0.550 \\
Mathematical levels obtained at Grade 12 (in percentages) & $-0.071^{*}$ \\
I have a positive attitude towards statistics as a subject & 0.041 \\
I have fear for statistics & $0.173^{* * *}$ \\
I prefer to attend statistics lectures in the morning & 0.026 \\
I attend statistics lectures mainly because I like the lecturer & -0.001 \\
I attend statistics lectures mainly because I like the subject & $-0.176^{* * *}$ \\
I easily understand the language used in the prescribed textbook & -0.060 \\
\hline Constant & $2.828^{* * *}$ \\
$R^{2}=$ & 0.180 \\
$F=$ & $9.361^{* * *}$ \\
\hline${ }_{*}^{* * *} p<0.01 ;{ }^{* *} p<0.05 ;{ }^{*} p<0.10$ &
\end{tabular}

There is a good model fit $(\mathrm{F}=9.361)$ and $18.0 \%$ of variation in cognitive capacity is explained by the three explanatory variables. How many times a student has repeated statistics, the levels obtained in the mathematical subject in Grade 12 (Matriculation), the fear for statistics and the subject's impact on students' lecture attendance are significant variables that influence the barrier 'cognitive capacity'. A positive $B$ value for repeating the statistics course variable imply that the more the times a student repeats the course, the greater the chances of having mental block and they can easily give up when solving statistics problems. The grades obtained at matriculation level are inversely proportional to the cognitive capacity of students. Students with higher mathematics grades at grade 12 level are less likely to experience mental block and they do not easily give up.

\section{Conclusions and Recommendations}

The purpose of this study is twofold, firstly is to identify the barriers to success in statistics. Second aim is to identify the influence of the course related factors on the identified barriers. The study identified six barriers to success in statistics which are categorised into three groups namely; situational, dispositional and organisational barriers. Cognitive capacity and disadvantaged background are classified as situational barrier. The factors, content difficulty and value of statistics are grouped as dispositional barrier while the study identified access to resources and support structures as barriers to success in statistics, classified as organisational barrier.

The regression model was used to identify the relationship between 'course related items' and the barrier cognitive capacity. The study has shown that the number of times the student has repeated the module statistics significantly influence the barrier cognitive capacity. The study seems to suggest that experiencing a mental block and easily give up a statistical problem is directly related to repeating the module.

Statistics anxiety is a complex problem; to ameliorate the discomfort the subject induces in students requires a great deal of research. Therefore, this study recommends that universities of technology offer pastoral services to nonscience students taking statistics as a module, implement bridging courses to students without mathematics at grade 12 and extend the module offering time. This study also recommends that universities do student counselling prior to enrolling students in a statistical module.

\section{References}

Aiken, L. R. (1996). Rating scales and checklists: Evaluating behavior, personality, and attitudes. New York: John Wiley \& Sons.

Baker, E., Paul, B., Darling-Hammond, L., Haertel, E., Ladd, H., Linn, R., Ravitch, D., Rothstein, R., Shavelson, R., \& Shepard, L. (2010). Problems with the Use of Student Test Scores to Evaluate Teachers. Economic Policy Institute.

Bell, J. A. (1998). International students have statistics anxiety too! Education, 118, 634.

Burton, K., Lloyd, M. G. \& Griffiths, C. (2010). Barriers to learning for mature students studying HE in an FE college. Journal of further and higher education. http://www.tandfonline.com/loi/cjfh20

Browne, M.W. (2001). An overview of analytic rotation in exploratory factor analysis. Multivariate Behavioral Research, 36, $111-150$.

Castles, J. (2004). Persistence and the adult learner: factors affecting persistence in Open University students. Active Learning in Higher Education 5, no. 2: 166-79. 
Cross, K.P. (1981). Chain and response model for participation in adult education. http://adultlearning.wikispaces.com/file/view IChain+of+Response+Model.doc.

Cross, K. P. (1981). Adults as learners. San Francisco: Jossey-Bass.

Darkenwald, G., \& Merriam, S. (1982). Adult education: Foundations of practice. New York: Harper and Row.

Davies, P., Osborne, M. \& Williams, J. (2002). For me or not for me? That is the question: a study of student's decision making and higher education. Norwich: Her Majesty's Stationery Office.

Department of Education (2012). National Diagnostic Report on Learner Performance http://www.education.gov.za

Doyle, L., \& Taylor, S. 2003. Adult learning pathways: raising aspirations and tackling barriers to progression. London: Learning Skills Development Agency.

Emmioglu, E., Capa-Aydin, Y., \& Cobanoglu, R. (2011). The relationship between graduate students' attitudes toward statistics and statistics achievement. Paper presented at National Congress of Educational Sciences, Cyprus International University, Lefkosa, Cyprus.

Estrada, A. \& Batanero, C. (2008). Explaining teachers' attitudes towards statistics: University of Lleida, University of Granada, Spain.

Galusha, J. M. (1998). Barriers to Learning in Distance Education. University of Southern Mississippi. http://www.tcom.ohiou.edu/ouln /Barriers to Learning in Distance Education.htm

Garcia, A. (2013). Cognitive, Affective and Behavioural Components that explain attitudes towards statistics. Journal of Mathematics Research. Vol 4, No 5, October 2012 pp 8-16. (2012) URL: http://dx.doi.org/10.5539/jmr.v4n5p8.

Giesbrecht, N. (1996). Strategies for Developing and Delivering Effective Introductory-Level Statistics and Methodology Courses, ERIC Document Reproduction Service, No. 393-668, Alberta, BC.

Hodkinson, P., G. Ford, R. H., \& Hodkinson, H. (2006). The significance of formal education and training in adults' lives. Working paper. Leeds: Learning Lives Research.

Kaiser, H.F. (1974). An index of factorial simplicity. Psychometrika, 39, 31-36.

Khavenson, T., Orel, E. \& Tryakshina, M. (2012). Procedia social and behavioral sciences. www.elsevier.com/locate/procedia

Malhotra, N. K. (2007). Marketing Research: An Applied Orientation. Upper Saddle River, NJ: Prentice-Hall.

Maxted, P. (1999). Understanding the barriers to learning: a guide to research and current thinking. London: Short Run Press.

McGivney, V. (1990). Education's for other people: access to education for nonparticipant adults. Leicester: National Institute of Adult Continuing Education (NIACE).

McLeod, D.B. (1992). Research on affect in Mathematics education: A reconceptualization. In D.A.Gouws (Ed.), Handbook of research on Mathematics teaching and learning. New York: Macmillan.

Murdock, N. (2013). Only 15\% of University students graduate.www.universityworldnews.com/article.php .Accessed on 11 December 2013.

Onwuegbzie, A.L., \& Wilson, V. A. (2003). Statistics Anxiety: Nature, aetiology, antecedents, effects, and treatment: A comprehensive review of the literature. Teaching in Higher Education, 8, 195-209. Doi:10.1080/1356251032000052447.

Shult, K. S. \& Koshino, H. (1998). Evidence of reliability and validity for Wise's attitude towards statistics scale. Educational and Psychological Measurement, 82(1), 27-31.

Slootmaeckers, K. (2012). Too afraid to learn?! Attitudes towards statistics as barrier to learning statistics and to acquiring quantitative skills. EPOS working paper.

Stammen, R. (1995). Using multimedia for distance learning in adult, career and vocational education. Information Series No. 362. Columbus, OH: The Ohio State University, ERIC Clearinghouse on Adult, Career, and Vocational Education. (ERIC Document Reproduction Service No. ED 384 828)

Tsao, Y.L (2006). Teaching with constructivist-based learning Method to describe student attitudes towards statistics, Taiwan.

Vanhoof, S., Kuppens, S., Castro Sotos, A.E., Verschaffel, L. \& Onghena, P. (2011). Measuring Statistics Attitudes Towards Statistics (SATS-36), Statistics Education Research Journal, 10(1), 35-51

Wilson, N. \& McClean, S. (1994). Questionnaire Design: A Practical Introduction. University of Ulster. Copies available from: UCoSDA, Level Six, University House, University of Sheffield, Sheffield S10 2TN. 